\title{
Case Files of the Toxikon Medical Toxicology Fellowship in Chicago: The Poisoned Anesthesiologist
}

\author{
Trevonne M. Thompson, $M D^{a}$, Steven E. Aks, $D O^{b}$
}

aThe Toxikon Consortium, Department of Emergency Medicine, University of Illinois at Chicago, Chicago, IL

bThe Toxikon Consortium, Department of Emergency Medicine, Cook County Hospital (Stroger) Chicago, IL

\section{CASE PRESENTATION}

A 58-year-old retired anesthesiologist presented unresponsive to the emergency department (ED). The patient's wife stated that she saw him as she was leaving the house at 8:00 a.m on the day of presentation, and he seemed well. A relative called the patient at 10:00 a.m. and noted that his speech was slurred. His wife returned home at 2:30 p.m. and noted that the doors to the house were locked. Subsequently she left because she did not have her key. She returned again at 5:30 p.m. and was unable to gain entry into the house. With the assistance of a locksmith, she entered the house to find the patient, in his study, unresponsive.

The patient's wife activated emergency medical services (EMS). Paramedics arrived to find the patient unresponsive, hypotensive, and bradycardic. He was immediately intubated. He had an undetectable blood pressure and undetectable pulse. He was resuscitated with $2 \mathrm{mg}$ each of intravenous atropine and epinephrine and rapidly transported. Upon arrival to the ED, he had a blood pressure of $70 / 40 \mathrm{mmHg}$, a pulse of $60 / \mathrm{min}$, and a rectal temperature of $34.4^{\circ} \mathrm{C}\left(94^{\circ} \mathrm{F}\right)$. On physical examination there were no external signs of trauma, pupils were $3 \mathrm{~mm}$ bilaterally with no reaction to light, and no skin breakdown or pressure ulcers were noted. The cardiopulmonary and abdominal exams revealed no gross abnormalities. The neurologic examination demonstrated a comatose patient with no purposeful movements and a Glasgow Coma Scale (GSC) of three.

The patient has a history of type 2 diabetes mellitus and hypertension. His medications included metformin $500 \mathrm{mg}$, amlodipine $5 \mathrm{mg} /$ benazepril $10 \mathrm{mg}$ capsules, atorvastatin $10 \mathrm{mg}$, extended-release metoprolol $50 \mathrm{mg}$, and losartan $50 \mathrm{mg}$. The patient's wife stated that he had no history of depression or suicide attempts.

The patient was further resuscitated with intravenous fluids, and a dopamine drip was titrated to maintain perfusion. The initial laboratory data are listed in Table 1. Hyperkalemia was treated with intravenous insulin and sodium bicarbonate. A computed tomography (CT) scan of the head was normal. A 12-lead EKG initially showed QRS duration of 100ms. After resuscitation, the QRS duration was $84 \mathrm{~ms}$. An EMIT urine drug screen was only positive for barbiturates.

\section{What are the unique characteristics of suicide attempts by physicians?}

Physician suicide rates have long been known to be higher than those among the general population [1-4]. Actual suicide rates are difficult to determine because suicide is a legal determination that requires a standard of proof: it is not a medical diagnosis [5]. As such, the forensic literature often differs from the medical literature regarding suicide rates. Because physicians may be more adept at disguising a suicide attempt, data about physician suicides is complicated [5]. However, recent studies have approximated physician suicide rates to be two-fold that of the general population, which has an annual suicide rate of approximately 11 per 100,000 people [5-7].

Thirty to $70 \%$ of those who attempt suicide have an affective disorder, substance abuse disorder, or schizophrenia [8]. Physicians, unfortunately, have a higher prevalence of depression and substance abuse than the general public $[6,8]$. This is in direct contrast to data about overall mortality; data that suggest physicians maintain an overall lower mortality rate than the general

Keywords: phenobarbital, overdose, poisoning

Notes: There was no outside funding of any kind used for this study.

Corresponding Author: Trevonne M. Thompson, MD, University of Illinois at Chicago College of Medicine, Department of Emergency Medicine, MC 724, College of Medicine East, Room 471, 808 S. Wood St., Chicago, IL 60612.

Email: tthompson001@md.northwestern.edu 


\section{Table 1: Initial Laboratory Data}

\begin{tabular}{|c|c|}
\hline \multicolumn{2}{|l|}{ Chemistry Profile } \\
\hline Sodium & $133 \mathrm{mEq} / \mathrm{L}$ \\
\hline Potassium & $7.1 \mathrm{mEq} / \mathrm{L}$ \\
\hline Chloride & $99 \mathrm{mEq} / \mathrm{L}$ \\
\hline Bicarbonate & $23 \mathrm{mEq} / \mathrm{L}$ \\
\hline Urea nitrogen & $14 \mathrm{mg} / \mathrm{dL}$ \\
\hline Creatinine & $2.7 \mathrm{mg} / \mathrm{dL}$ \\
\hline Glucose & $350 \mathrm{mg} / \mathrm{dL}$ \\
\hline \multicolumn{2}{|c|}{ Complete Blood Count } \\
\hline White blood cells & $15,100 / \mathrm{mm} 3$ \\
\hline Hemoglobin & $14.8 \mathrm{~g} / \mathrm{dL}$ \\
\hline Hematocrit & $44.70 \%$ \\
\hline Platelets & $204,000 / \mathrm{mm} 3$ \\
\hline \multicolumn{2}{|l|}{ Arterial Blood Gas } \\
\hline $\mathrm{pH}$ & 7.18 \\
\hline pCO2 & $45 \mathrm{mmHg}$ \\
\hline pO2 & $285 \mathrm{mmHg}$ \\
\hline Bicarbonate & $16.8 \mathrm{mEq} / \mathrm{L}$ \\
\hline \multicolumn{2}{|l|}{ Urine Drug EMIT } \\
\hline Amphetamines & negative \\
\hline Barbiturates & positive \\
\hline Benzodiazepines & negative \\
\hline Phencyclidine & negative \\
\hline Opitates & negative \\
\hline Cannabinoids & negative \\
\hline \multicolumn{2}{|l|}{ Serum Toxicology } \\
\hline Ethanol & not detectable \\
\hline Salicylates & $<5 \mathrm{mg} / \mathrm{dL}$ \\
\hline Acetaminophen & $<1 \mathrm{mcg} / \mathrm{mL}$ \\
\hline
\end{tabular}

public [3]. It should be noted that physicians who attempt suicide are more successful than the general population [8]. Anesthesiologists carry an increased risk of suicide. One recent study determined that anesthesiologists have twice the suicide rate as internists [4]. Other high-risk specialties include psychiatry and emergency medicine [8].

Physicians who attempt suicide pose diagnostic challenges for the emergency physician or clinical toxicologist. Physicians poison themselves more often than the general population [8]. Furthermore, they may overdose on substances available to them via their office or laboratory. One report noted the 5 most common substances laboratory personnel and physicians used in overdose: phenobarbital, carbon monoxide, cyanide, azides, and methemoglobin-inducing substances [9].

\section{Describe the historical features of barbiturate overdose.}

Historically, the treatment for barbiturate overdose has changed. In the 1930s and 1940s, the use of analeptics was considered the standard of care. Analeptics were thought to stimulate the respiratory and circulatory centers in the central nervous system, thereby reversing the effects of barbiturate overdose [10]. The mortality rate from barbiturate overdose, however, remained high despite this therapy. In the 1950s, the "Scandinavian method" was developed and became the basis for the supportive care model used by modern toxicologists [10]. This method ascribed less importance to attempting pharmacologic reversal of barbiturate overdose with analeptic agents, instead focusing on providing renal, circulatory, and respiratory support through the poisoning. This approach was initially criticized as being "pharmacologic nihilism," but a close examination of the Scandinavian method reveals no real basis of pharmacologic nihilism [10].

In describing the Scandinavian method, Clemmesen and Nilsson first outlined the reasons for death in barbiturate-poisoned patients: respiratory failure, circulatory collapse, and renal failure [10]. Their method involved a close observation of a patient's vital signs, monitoring urine output, maintaining a patient airway (including tracheal intubation when necessary), providing pulmonary toilet, and the routine measurement of the patient's acid-base status. In an attempt to maintain normal physiologic parameters the goal of such close monitoring was to promptly detect and correct aberrancies. This approach reduced the morality of barbiturate overdose from $20 \%$ to $1-2 \%$ [10]. The Scandinavian method is an early description of the supportive care model used in modern clinical toxicology.

Sedative-hypnotic drugs have consistently been among the most common drugs that lead to fatal poisonings $[11,12]$. In recent decades, therapeutic barbiturate use and barbiturate overdose have declined, largely in part to the supplanting of barbiturates by safer sedative-hypnotic agents such as benzodiazepines $[11,13,14]$. In fact, more benzodiazepine overdoses (a ratio 20fold greater than barbiturate overdoses) are reported to the American Association of Poison Control Centers [14].

\section{CASE CONTINUATION}

After considering the patient's occupation and the positive barbiturate screen, the emergency physician (EP) ordered a quantitative serum phenobarbital level and received a reading of 151.5 $\mathrm{mg} / \mathrm{L}$. At this point, our toxicology service (via the poison center) was consulted. The EP simultaneously consulted the nephrology service. The administration of multiple-dose activated charcoal (MDAC) was recommended once vital signs were stabilized. The nephrology service independently decided to perform hemodialysis (HD). The patient underwent 2 rounds of HD, lasting 4.5 and 
6 hours, respectively. The phenobarbital level was $90 \mathrm{mg} / \mathrm{L}$ after the first session and $30 \mathrm{mg} / \mathrm{L}$ after the second session.

\section{What role does urinary alkalinization play in the treatment of phenobarbital overdose?}

Urinary alkalinization has been employed as a treatment for phenobarbital poisoning since the first half of the 20th century. An alkaline urinary $\mathrm{pH}$ promotes hydrogen ion dissociation from weak acids, rendering the consequent ionized conjugate bases less accessible to reabsorption at the distal renal tubule, and thereby enhancing urinary excretion. This process is often referred to as ion-trapping. With a pKa of 7.2, phenobarbital, a long-acting barbiturate, is a weak acid. It is dissimilar from pentobarbital and secobartibal, both with pKa values of approximately 8.1 [15]. In a 1957 dog model, Waddell demonstrated that the change in the undissociated form of phenobarbital after alkalinization in the physiological range was greater than that of other barbituric acids [16]. Along with urine flow, the renal clearance of phenobarbital increased and this clearance was enhanced in alkaline urine [16]. Diuresis was induced by water via stomach tube, intravenous mercaptomerin sodium, or intravenous sodium sulfate [16].

In 1960, Lassen and Copenhgen described the clinical series of forced alkaline diuresis in 14 patients [17]. Urea was used as the diuretic agent, and lactate was used as the alkalinizing agent. Approximately $200 \mathrm{~mL}$ of the solution was given for the first 3-4 hours, followed by $100 \mathrm{~mL}$ solutions per hour thereafter. Lassen and Copenhgen noticed that forced urinary alkaline diuresis increased the elimination rate of several barbiturate compounds compared with other controls [17]. Complications in 2 patients included intracerebral hemorrhage, attributed to excessive dehydration, and pulmonary edema.

In 1963, Myschetzky described a similar regimen of alkaline diuresis using urea and lactate [18]. Compared to previously managed patients who did not undergo alkaline diuresis, his work demonstrated an improvement in barbiturate elimination time. As a result of improved elimination time via the regimen, Myschetzky estimated a marked reduction in length of coma. This study was not randomized, and the actual method for assessing duration of coma was not described. The authors concluded that "the present form of active therapy of barbiturate poisoning cannot replace the fundamental supportive therapy aimed at maintaining adequate ventilation and circulation" and that urinary alkalinization "is never a vitally indicated treatment" [18].

In a study of osmotic diuresis and alkalinization therapy using mannitol and bicarbonate, Bloomer demonstrated that the elimination rate of phenobarbital approximately doubled. This was not the case with short acting barbiturates such as secobarbital or pentobarbital [15].

Linton et al. investigated the effect of forced diuresis on phenobarbital elimination, comparing the effectiveness of furosemide, chlorthiazide, and mannitol. A simple fluid regimen was effective in enhancing elimination, and the type of diuretic was not important. Their study also confirmed that the clearance of phenobarbital was improved with alkaline urine [19]. These results were similarly confirmed by Mawer, who also found that mannitol had no additional benefit over furosemide [20].

Early descriptions of urinary alkalinization were often mixed with the terms "forced diuresis", "forced alkaline diuresis", and "alkaline diuresis". Forced diuresis generally implied the use of intravenous fluids and a diuretic. Forced alkaline diuresis implied the use of intravenous fluids, a diuretic, and an alkalinizing agent such as lactate or bicarbonate. Alkaline diuresis usually implied the use of intravenous fluids and an alkalinizing agent.

\section{What is the historical basis for using activated charcoal in the treatment of barbiturate overdose?}

Activated charcoal effectively adsorbs phenobarbital. When taken immediately after ingestion of the pills, a 50-gram oral dose of activated charcoal has been demonstrated to almost completely prevent the absorption of phenobarbital, carbamazepine and phenylbutazone [21]. Additionally, multiple-dose activated charcoal (MDAC) increased the elimination of phenobarbital in volunteers five-fold [21]. In two reported cases of phenobarbital overdose treated with MDAC, the half-life of phenobarbital was less than 24 hours [22]. When compared to historical controls, the authors also noted a shortened duration of coma [22].

In 1982, Berg demonstrated convincing evidence of activated charcoal's efficacy in eliminating phenobarbital [23]. In this study, orally administered activated charcoal significantly increased the clearance of intravenously administered phenobarbital in volunteers. One hundred eighty grams of activated charcoal was given in divided doses over 3 days. The serum half-life reduced from 110 hours in the control group to 45 hours in the treatment group. This study argues for the development of a concentration gradient between the blood and the intraluminal gastrointestinal fluid, whereby phenobarbital continuously enters the gut and is adsorbed by activated charcoal-allowing for increased elimination via the gastrointestinal tract [23]. This concept has been termed "gastrointestinal dialysis", or "gut dialysis", by others [24].

One of the most important investigations in this area was carried out by Pond [25]. In 10 comatose patients intoxicated by phenobarbital, 5 received single-dose activated charcoal, and 5 received MDAC. In the single-dose (SD) group the mean elimination half-life was 93 hours; in the MDAC group the elimination half-life was 36 hours-a difference that was statistically significant. There was, however, no statistically significant difference in the length of time of mechanical ventilation (39 hours in the SD group and 48 hours in the MDAC group) or time spent in the hospital. Most patients were only extubated at particular times during the day (e.g. the morning), and there were no consistent weaning parameters. This creates potentially confusing factors. Although there was a significant increase in the elimination rate of phenobarbital, no documentation of a clinically significant difference in patient outcome could be demonstrated [25]. 
A case series by Boldy et al. documented very rapid elimination half-lives in 6 patients (suffering from phenobarbital overdose) treated with MDAC [26]. Elimination half-lives ranged from 3.4 to 10.2 hours. There was no control group in this series. The authors argue that the half-lives in these patients are much lower than expected historical controls and that the time to resolution of coma was much shorter than would have been predicted without MDAC [26].

\section{How do activated charcoal and alkaline diuresis compare in the treatment of phenobarbital overdose?}

In a cross-over volunteer study using sub-therapeutic doses of phenobarbital, Frenia et al. compared the two methods of enhanced elimination to a control group [27]. The volunteers ingested $5 \mathrm{mg} / \mathrm{kg}$ of phenobarbital and, in a cross-over design, were subjected to no therapy, urinary alkalinization (to maintain a urine $\mathrm{pH}$ between 7.5 and 8), and MDAC (50gm of activated charcoal followed by 25 gm every 4 hours). The half-life of phenobarbital was 148 hours in the control group, 47 hours in the alkalinization group, and 19 hours in the MDAC group. Multiple-dose activated charcoal was the superior treatment in this study [27].

Ebid et al. compared three groups [MDAC (group I), urinary alkalinization (group II), and (group III), a combination of both] on phenobarbital elimination in a series of poisoned patients [28]. The mean duration of mechanical ventilation was 40.2 hours in group I (MDAC), 79.4 hours in group II (urinary alkalinization), and 51.7 hours in group III (a combination of the two therapies). Likewise, the mean time to achieve mental alertness and orientation was 24.4 hours in group I, 50.6 hours in group II, and 37.2 hours in group III; the mean time until extubation was 29.7 hours in group I, 54.2 in group II, and 43.2 hours in group III. Compared to groups II and III, the MDAC group (group I) demonstrated a statistically significant shorter duration of mechanical ventilation, reduced time to mental alertness, and reduced time until extubation. Similarly, the combined therapy group (group III) showed a statistically significant difference in similar parameters when compared to the alkalinization group (group II). The elimination half-life of phenobarbital was 38.6 hours for group I, 81.1 hours for group II, and 51.4 hours for group III. These data suggest that the use of MDAC and supportive care, without urinary alkalinization, is justified [28].

When directly compared, multiple-dose activated charcoal appears to be superior to urinary alkalinization for enhancing the elimination of phenobarbital. There is insufficient data regarding the combined use of MDAC and urinary alkalinization. Revisiting the classic paper by Clemmesen and Nilsson detailing the Scandinavian method, where mortality dropped from $20 \%$ to $1-2 \%$ with aggressive supportive care, it would seem unlikely that either therapy had a dramatic effect on mortality. Multiple-dose activated charcoal appears, in these small studies, to reduce intensive care unit time and the time to discharge; however, larger trials would be needed for further assessment of these parameters.

\section{What about extracorporeal methods of elimination?}

Investigations have demonstrated the efficacy of extracorporeal methods for the elimination of phenobarbital [29,30]. In 1966, Setter demonstrated the comparative clearance rates of phenobarbital by hemodialysis $(30 \mathrm{ml} / \mathrm{min})$, peritoneal dialysis (4-8 $\mathrm{ml} / \mathrm{min}$ ), and diuresis (3-4 ml/min), [29]. In 1986, Jacobsen demonstrated a $78-88 \%$ reduction in half-life in three cases of phenobarbital poisoning when hemoperfusion was performed [30]. The half-lives were 7.2 to 11.1 hours during hemoperfusion, and half-lives increased from 48 to 82 hours after hemoperfusion was discontinued [30]

There has been debate as to whether hemoperfusion is preferable to hemodialysis in patients poisoned by phenobarbital. Hemoperfusion is often limited because of its lack of availability in many hospitals; conversely, hemodialysis is accessible in most hospitals. Additionally, the newer high-flux dialysis machines possess remarkable clearance rates. Palmer documented the clearance range of a high-flux dialysis from 144 to $188 \mathrm{ml} / \mathrm{min}$ in a case of severe phenobarbital intoxication [31]. The half-life reported in the Palmer case was 3.2 hours while the patient was receiving dialysis and an undescribed alkalinization procedure [31]. Jacobs also reported the efficacy of conventional hemodialysis in a case of phenobarbital overdose, arguing for the use of hemodialysis as an excellent alternative to hemoperfusion [32].

Other procedures, such as continuous arteriovenous hemoperfusion (CAVHP) and continuous venovenous hemodiafiltration (CVVHDF), have also been documented as effective modalities to improve the clearance of phenobarbital after overdose $[33,34]$. These procedures have the relative advantage of being usable in patients with hypotension. A disadvantage is that they require specialized nursing care.

There is no clear answer as to who should receive dialysis. The literature suggests that patients suffering from severe phenobarbital intoxication should receive hemodialysis because it can clearly shorten the elimination time of the drug. Fifty years ago, Setter considered the following criteria to be indications for dialysis: 1) a dangerously high blood level (>80 mg/L); 2) progressive clinical deterioration with conservative therapy, particularly with decreasing respiratory or cardiovascular function; 3 ) prolonged coma, especially in the elderly or with the development of severe complications; 4) impairment of normal routes of excretion (refractory hypotension, renal failure or hepatic failure) [29]. One text recommends that hemodialysis or hemoperfusion should be considered for a phenobarbital concentration of $100 \mathrm{mg} / \mathrm{L}$ or greater [35]. However, most sources suggest making this determination on clinical grounds. Patients chronically on phenobarbital, for example, can tolerate higher levels, making a strict numerical cut-off point difficult to determine. The decision to use dialysis should be based on the clinical situation because no clinical trials have clarified the proper indications for extracorporeal removal methods in cases of phenobarbital toxicity. 


\section{CASE CONTINUATION}

On day 2 of his hospital stay, the patient was extubated: he was notedly confused and intermittently agitated. Over the next 4 days, the patient showed progressive improvement in mental status, ultimately returning to his baseline. He was discharged to a psychiatric facility on his seventh hospital day with no residual neurologic deficits.

\section{CONCLUSION}

Suicide attempts by health care workers are very serious because these patients have the knowledge of and access to potentially lethal substances. Our patient presented with hypotension and hemodynamic instablility. He was treated with multiple-dose activated charcoal and 2 rounds of hemodialysis. While there was rapid toxicokinetic improvement and extubation on day 2 of his hospital stay, he had prolonged altered mental status, illustrating the long-acting effects of phenobarbital. It remains unclear exactly how our medical treatment regimens alter the clinical course of phenobarbital poisoning. We are indebted to Clemmesen and Nilsson for their description of the Scandinavian Method and the resulting reduction in morbidity from sedativehypnotic poisoning. Further research is needed to define the precise clinical benefit achieved from additional therapeutic modalities in treating such poisonings.

The authors have no potential conflicts of interest to report.

\section{REFERENCES}

1. Lindeman S, Laara E, Vuori E, Lonnqvist J. Suicides among physicians, engineers and teachers: the prevalence of reported depression, admissions to hospital and contributory causes of death. Acta Psychiatr Scand. 1997;96:68-71.

2. Hawton K, Clements A, Sakarovitch C, Simkin S, Deeks JJ. Suicide in doctors: a study of risk according to gender, seniority and specialty in medical practitioners in England and Wales, 1979-1995. J Epidemiol Community Health. 2001;55:296-300.

3. Frank E, Biola H, Burnett CA. Mortality rates and causes among U.S. physicians. Am J Prev Med. 2000;19:155-159.

4. Alexander BH, Checkoway H, Nagahama SI, Domino KB. Cause-specific mortality risks of anesthesiologists.

Anesthesiology. 2000;93:922-930.

5. Swanson SP, Roberts LJ, Chapman MD. Are anaesthetists prone to suicide? A review of rates and risk factors. Anaesth Intensive Care. 2003;31:434-445.

6. Schernhammer ES, Colditz GA. Suicide rates among physicians: a quantitative and gender assessment (meta-analysis). Am J Psychiatry. 2004;161:2295-2302.

7. Tondo L, Albert MJ, Baldessarini RJ. Suicide rates in relation to health care access in the United States: an ecological study. J Clin Psychiatry. 2006;67:517-523.
8. Schernhammer E. Taking their own lives-the high rate of physician suicide. N Engl J Med. 2005;352:2473-2476.

9. Binder L, Fredrickson L. Poisonings in laboratory personnel and health care professionals. Am J Emerg Med.

1991;9:11-15.

10. Clemmensen C, Nilsson E. Therapeutic trends in the treatment of barbiturate poisoning. The Scandinavian method. Clin Pharmacol Ther. 1961;2:220-229.

11. Buckley NA, McManus PR. Changes in fatalities due to overdose of anxiolytic and sedative drugs in the UK (1983-1999). Drug Saf. 2004;27:135-141.

12. Johns MW. Self-poisoning with barbiturates in England and Wales during 1959-74. Br Med J. 1977;1:1128-1130.

13. Osselton MD, Blackmore RC, King LA, Moffat AC. Poisoning-associated deaths for England and Wales between 1973 and 1980. Hum Toxicol. 1984;3:201-221.

14. Watson WA, Litovitz TL, Rodgers GCJ, Klein-Schwartz W, Reid N, Youniss J, Flanagan A, Wruk KM. 2004 Annual report of the American Association of Poison Control Centers Toxic Exposure Surveillance System. Am J Emerg Med. 2005;23:589-666.

15. Bloomer HA. A critical evaluation of diuresis in the treatment of barbiturate intoxication. J Lab Clin Med.

1966;67:898-905.

16. Waddell WJ, Butler TC. The distribution and excretion of phenobarbital. J Clin Invest. 1957;36:1217-1226.

17. Lassen NA, Copenhgen MD. Treatment of severe acute barbiturate poisoning by forced diuresis and alkalinisation of the urine. Lancet. 1960;2:338-342.

18. Myschetzky A, Lassen NA. Urea-Induced, Osmotic Diuresis and Alkinization of Urine in Acute Barbiturate Intoxication. JAMA. 1963;185:936-942.

19. Linton AL, Luke RG, Briggs JD. Methods of forced diuresis and its application in barbiturate poisoning. Lancet.

1967;2:377-379.

20. Mawer GE, Lee HA. Value of forced diuresis in acute barbiturate poisoning. Br Med J. 1968;2:790-793.

21. Neuvonen PJ, Elonen E. Effect of activated charcoal on absorption and elimination of phenobarbitone, carbamazepine and phenylbutazone in man. Eur J Clin Pharmacol.

1980; $17: 51-57$.

22. Goldberg MJ, Berlinger WG. Treatment of phenobarbital overdose with activated charcoal. JAMA. 1982;247:2400-2401.

23. Berg MJ, Berlinger WG, Goldberg MJ, Spector R, Johnson GF. Acceleration of the body clearance of phenobarbital by oral activated charcoal. N Engl J Med. 1982;307:642-644.

24. Levy G. Gastrointestinal clearance of drugs with activated charcoal. N Engl J Med. 1982;307:676-678.

25. Pond SM, Olson KR, Osterloh JD, Tong TG. Randomized study of the treatment of phenobarbital overdose with repeated doses of activated charcoal. JAMA. 1984;251:3104-3108.

26. Boldy DA, Vale JA, Prescott LF. Treatment of phenobarbitone poisoning with repeated oral administration of activated charcoal. Q J Med. 1986;61:997-1002. 
27. Frenia ML, Schauben JL, Wears RL, Karlix JL, Tucker CA, Kunisaki TA. Multiple-dose activated charcoal compared to urinary alkalinization for the enhancement of phenobarbital elimination. J Toxicol Clin Toxicol. 1996;34:169-175.

28. Mohammed Ebid AH, Abdel-Rahman HM.

Pharmacokinetics of phenobarbital during certain enhanced elimination modalities to evaluate their clinical efficacy in management of drug overdose. Ther Drug Monit. 2001;23:209-216.

29. Setter JG, Maher JF, Schreiner GE. Barbiturate intoxication. Evaluation of therapy including dialysis in a large series selectively referred because of severity. Arch Intern Med.

1966;117:224-236.

30. Jacobsen D, Wiik-Larsen E, Dahl T, Enger E, Lunde PK. Pharmacokinetic evaluation of haemoperfusion in phenobarbital poisoning. Eur J Clin Pharmacol. 1984;26:109-112.

31. Palmer BF. Effectiveness of hemodialysis in the extra- corporeal therapy of phenobarbital overdose. Am J Kidney Dis. 2000;36:640-643.

32. Jacobs F, Brivet FG. Conventional haemodialysis significantly lowers toxic levels of phenobarbital. Nephrol Dial Transplant. 2004; 19:1663-1664.

33. Lin JL, Jeng LB. Critical, acutely poisoned patients treated with continuous arteriovenous hemoperfusion in the emergency department. Ann Emerg Med. 1995;25:75-80.

34. Lal R, Faiz S, Garg RK, Baweja KS, Guntupalli J, Finkel KW. Use of continuous venovenous hemodiafiltration in a case of severe phenobarbital poisoning. Am J Kidney Dis.

2006;48:e13-5.

35. Winchester JF. Extracorporeal removal of toxic substances. In: Brent J, Wallace KL, Burkhart KK, Phillips SD, Donovan JW, eds. Critical Care Toxicology. Philadelphia: Elsevier Mosby; 2005. 